\title{
Prospective Early Childhood Teachers' Understandings on the Nature of Science in Terms of Scientific Knowledge and Scientific Method
}

\author{
Ümit Duruk ${ }^{1, *}$, Abuzer Akgün ${ }^{1}$, Fuat Tokur ${ }^{2}$ \\ ${ }^{1}$ College of Education, Adıyaman University, Turkey \\ ${ }^{2}$ Adiyaman Science \& Art Center, Turkey
}

Copyright $\bigcirc 2019$ by authors, all rights reserved. Authors agree that this article remains permanently open access under the terms of the Creative Commons Attribution License 4.0 International License

\begin{abstract}
The purpose of this study was to explore the understandings of prospective early childhood teachers on scientific knowledge and scientific method. The study was interpretive in nature. The data were collected through various open-ended questions with subsequent auxiliary ones directed towards ten participants during a combination of in-depth focus group interviews and getting peer feedbacks in this process. Conversations and discussions among the participants were tracked on a tape recorder during the sessions and translated verbatim. The study focused on convenience and criterion sampling. As a criterion, academic achievement (accumulated GDA's) was considered, and the participants were assigned to the final sample this way. The data were analyzed in accordance with the conceptual framework of Marshall and Rossman [1] using an analytical task of qualitative approach. All data that were described, categorized and related to each other in the analysis are given in categories as well as emergent codes. Views of the participants were related to each other in an interpretive manner. Based on the results, the implications and the directions for further study are discussed.
\end{abstract}

Keywords Nature of Science, Scientific Knowledge, Scientific Method

\section{Introduction}

The current popularity of scientific literacy has widely experienced a noticeable rise over the past decades $[2,3]$. Many reform movements and related documents considered scientific literacy as the prominent part of science education $[4,5]$. Scientific literacy requires, in its most general definition, understanding what kind of scientific way of thinking a scientist would follow by values that are paid attention to and assumptions grounded on the process of constructing scientific knowledge, as well as the science content knowledge given in any curriculum. As such, fostering scientific literacy empowers students to understand the nature of science (NOS, hereafter) $[6,7,8]$. A major factor in the continuing appeal of NOS has been the fact that it is a critical component of curricula. There is an agreement on the fact that NOS actually includes a wide variety of tenets both in the context of science and its implications called as scientific enterprise even though it does not have a specific definition that is mutually accepted $[9,10,11,12]$. The uncertainty surrounding the definition of NOS stems from the facts that it is handled as a complex and multidimensional concept, and it does not have an extent that may be applied to all situations at the same time $[13,14,15]$. Generally speaking, according to Lederman [6], with his most appreciated and cited description, NOS refers to the epistemology of science, science as a way of knowing as well as the values and beliefs inherent to the development of scientific knowledge. However, scholars share a common wisdom about NOS in a specific context. These views regarding NOS are constructed on the understanding that scientific knowledge is tentative (subject to change), empirically based, subjective and socially embedded as well as involving explanations produced by human imagination and creativity, revealing the difference between observations and inferences, and finally referring to the relationships between laws and theories $[3,16,17,18]$. These tenets of NOS focus heavily on such contemporary views of NOS [5]. However, NOS goes beyond this description and refers to what science is or not, how scientists work, under what ontological and epistemological constraints science functions and how science interacts with the society in a broader sense [19]. Science, which is a historical-social phenomenon, is intertwined with the history of science, philosophy of science, sociology of science and psychology of science as 
well as epistemological underpinnings on which it is based [20]. In other words, NOS is an interdisciplinary concept, which evaluates some of the views in various scientific fields in a hybrid structure, which is shaped under the influence of these views and valued under certain epistemological and ontological limitations by the knowledge constructed by many scientific and pseudoscientific means $[6,21]$.

It is a critical characteristic that teachers have sufficient NOS understandings and can directly teach NOS [8]. Evidence from research consistently indicated that students and even in-service teachers are lacking in informed understanding of NOS $[6,9,22,23,24,25]$. The basic reason for this could be the fact that the curriculum provides a limited degree of development for the improvement of students' understandings of NOS in terms of teaching NOS, and the teachers who are the implementers of these curricula do not have enough positive beliefs about teaching NOS [26, 27, 28]. Based on this failure in development, insufficient teaching time, focusing on teaching science content knowledge rather than NOS and the lack of practical opportunities for teachers for developing pedagogical content knowledge for NOS may be shown as examples for situations in the context of NOS courses [21, 29, 30, 31]. However, it is clear from recent studies that prospective and in-service teachers can develop strategies that positively influence students' NOS understandings [32, 33, 34], otherwise, their future progress in relation to NOS might be stifled. This evidence provides valuable insights into the persisting problem of NOS instruction failing to improve student achievement. In practice, it is seen that very few teachers effectively teach NOS [35]. The cognitive and affective characteristics of teachers as well as the contextual limiters mentioned in this case are also effective. As noted earlier, the orientation of teachers' beliefs about teaching NOS has an important role in their classroom practices towards NOS [36]. This is because it may be stated that teachers who do not believe that they can change students' NOS understandings perform science teaching mostly based on science content knowledge, and thus, they do not consider NOS learning outcomes as teaching objectives. A similar situation has also been reported in the studies conducted with prospective science teachers and primary school teachers. It was understood that, similar to prospective science teachers, primary school teachers also have difficulty in this case. With that in mind, the main question to be asked here on the preschool level is whether or not young students can gain appropriate NOS understandings proposed by AAAS [16] and proposed to be taught on the K-2 level [29]. When the literature of cognitive psychology is examined, it is seen that the cognitive development of students' progresses in accordance with their developmental stages was conceptualized by Piaget. $\mathrm{He}$ actually posits that students cannot develop any understanding about NOS until they reach the last stage of intellectual development in which adolescents ponder abstract concepts and relationships. Contrary to this widespread view, Metz [37] claimed that this fundamental assumption in developmental psychology would also limit teaching NOS. According to the author, learning environments without inquiry lack the potential triggering effect on the development of understandings on NOS. Accordingly, teachers tend to use scientific process skills that they see as an effective way to construct more concrete knowledge rather than facilitating inquiry in terms of teaching in the classroom. An understanding of NOS cannot be expected to develop in a learning environment, which offers concrete experiences based on scientific process skills but is not suitable for making explanations about questioning. This is because inquiry is the leading force of the efforts put forward in the development of understanding on modern science. The idea that younger students cannot develop NOS understandings should be abandoned, because it has been seen that primary school students develop their understandings on creativity, being theory-laden and being based on tenets of inferences. Moreover, it has been determined that these understandings are reflected in the daily lives of students [38]. It was found that, in addition to primary school students, early childhood students' NOS understandings are developed [33, 39, 40]. For this reason, the idea that K-2 competencies are attainable on the preschool level has gained importance. This situation has paved the way to question the level of the NOS understandings of prospective early childhood teachers who are likely to perform this profession in the near future. This is because a teacher who has an inadequate understanding of NOS has little chance of developing such an understanding in students [41]. In the early childhood period where the initial observations of scientific facts are made, teachers need to prepare inquiry-based teaching environments for their students and structure an epistemological basis for scientific knowledge constructed through scientific intervention in a scientific discourse that they can understand. In order to perform this construction in a scientifically correct manner, as mentioned earlier, it is necessary for teachers to recognize the criteria for what science is and what it is not and be informed about under which epistemological limitations scientific activities are shaped. In order to understand the complex nature of the aforementioned situations, this study was carried out with an in-depth research of the understanding of NOS in a theoretical and conceptual framework.

\subsection{Theoretical Framework and Relevant Literature}

To frame this study, which was anchored conceptually by contemporary NOS understandings, two guiding concepts may be mentioned. The first is the 
understandings of NOS. These understandings are shaped under the understandings of nature of science. This indicates the assumption that scientific knowledge is also shaped under the limiting factors that are inherent to science. Scientific knowledge is the linguistic expressions that emerge in the form of propositions. These expressions are based on a logically deep analysis of information systems forming a basis to understand the concepts that make up that proposition, determine the relationships between concepts and the entire process of constructing scientific knowledge. For this reason, science is both a mental activity on the one hand and an operational activity on the other hand [42]. Additionally, science sets out from robust theories rather than uncertain pathways. The source, accuracy and boundaries of the scientific knowledge are connected to an epistemological origin that is open to be questioned at all times. Therefore, the epistemological elements of scientific knowledge are closely linked to the logical pattern that sets forth that knowledge [20]. Students need to internalize and make a commitment to those epistemological underpinnings of scientific knowledge. Scientific inquiry leads to this deeply-involved process and accounts for the main learning objective in science education [43]. Alongside the development of epistemological relativism that leads to contemporary reality perceptions, it might be stated that positivism, which is dominant in scientific fields, has been gradually replaced with relativity in science. In other words, it is observed that the rationale for the legitimacy of scientific knowledge evolves towards the idea that various perspectives may be valid at the same time rather than true/false dichotomy. This reversal leads to a major paradigm shift [26]. Paradigm shift is important because every paradigm creates its own scientific criteria [44]. While the positivist paradigm is based on the logic of validation in the question of scientificness, it may be stated that relative paradigms move away from this view over time. It is seen that the relative paradigm on the rise defines the reality as complex and argues that the exact results about the facts cannot be predicted. Thus, it may be stated that concepts related to relative science paradigm such as context, subjective reality, pluralism, partial knowledge, value-added results and interpretation are prominent in contemporary social sciences studies [45].

With the better understanding of the role of psychological and sociological factors in the process of making scientific explanations especially after 1980s, it may be stated that the positivist science paradigm that focuses on scientific process skills has entered into a serious crisis. Finally, science education scholars have become aware of this situation in 1990s and contributed to a moderate shift to the relative science paradigm by introducing various criteria for science education. Depending on the criteria published in this direction [16], the idea that the understanding of the three basic components should be improved has come to the fore for the development of understandings on NOS. The facts in the natural world are understandable, and science cannot find complete responses to all questions. Scientific inquiry may be based on evidence, as well as imagination during the discovery of explanations, and science is shaped in a social environment [26]. However, even the findings of recent studies reported that students, teachers and prospective teachers have inadequate NOS understandings. In these studies that are based on the conceptual change approach, it was concluded that there are several misconceptions that hinder the development of appropriate NOS understandings. In a cornerstone study in the relevant literature, McComas [21] described ten myths of science. The first one is the general idea that hypotheses turn into theories that will later turn into laws. Because there is an increasing number of units of evidence, students who have this idea think that hypotheses turn into theories and theories ultimately turn into laws that are the proven types of knowledge [46]. According to these students, the laws have been sufficiently corroborated, and therefore, they are the most valuable and scientific type of knowledge in this trilogy. Therefore, they attach less importance to hypotheses and theories than laws $[47,48,49,50]$. It is seen that this idea feeds on many sources in daily life. In many conversations among mass media, television, textbooks or groups of friends, theories are defined as being far from practice and refer to individuals' own ideas. It may be stated that this situation led to the dissemination of the idea that theories are less scientific than laws, and they have not yet fully matured. In fact, theories suppose that non-observable entities exist, and they cannot be directly tested. They are as valid and reliable as scientific laws [51]. Theories may also be described as coherent systems of many explanations [52]. What distinguishes theories from others is that they have a high predictive power. Thus, observable results may be obtained for phenomena and characteristics that cannot be directly observed. This way, scientific explanations, which are the aim of scientific activities, may be reached [53]. Another general idea is that scientific knowledge has been proven and therefore cannot be changed. As mentioned, laws are considered as proven knowledge. McComas [21] argued that the logic of proofing for mathematics is different from science, and few people are aware of this. When considered in the context of natural sciences, Yildirım [42] referred to science as efforts of describing, predicting and explaining what is happening. The accuracy of the propositions in this field is tested by revisiting cases. During the testing process, observations, experiments and measurements are used. The data obtained from observations and experiments are interpreted, and inferences are made. Explanations claimed to be scientific are reached by passing the implications of the depicted phenomena through the lens of theoretical frameworks. In addition to these two views, there is a general idea that there is a 
universally accepted scientific method. Those who hold this view believe that scientists always achieve the correct and reliable results by applying the same steps during their scientific activities. As it is the case with the general idea that theories can turn into laws, textbooks have a great influence on the formation of this general idea. The fact that textbooks often describe the performance of scientific activities like a cookbook deepens this view. In contrast to the reductionist understanding of science based on the Novum Organum, written by Francis Bacon, there is a need for imagination and creativity rather than strict methodological commitment in science [13]. The multitude of evidence obtained by scientific methods can make a law or theory more valid and reliable, but it can never prove them forever [17]. One of the common general ideas is that experiments, which are technical procedures based on cause-and-effect relationships, are seen as a single and perfect way to reach scientific knowledge. It is not possible to conduct an experiment in many areas of the social sciences. In other words, the social sciences can access scientific knowledge without experimenting. That is, no matter how careful the experiments are conducted, experiments are not the only evidence-gathering tool in the scientific field. Moreover, science is a far more comprehensive activity than the collection of pieces of evidence one by one. An experiment is a useful tool in producing manipulated observations in this comprehensive activity.

The second is the understandings of the scientific method. Especially in terms of natural sciences, it is important whether or not scientific knowledge is appropriate for the facts rather than how it is expressed. Therefore, there is an explicit link between the natural sciences and the scientific method. This vigorous interplay was often framed by the notion that there is no single scientific method that produces empirical evidence to explain scientific phenomena [18]. However, prospective teachers see experiments as a means of proving the accuracy of knowledge rather than the construction of knowledge. This situation increases its disruptive effect by using ready-made instructions in laboratory courses that are offered at universities [54].

It is seen that there are many studies in the literature on the nature and teaching of science, and these studies vary in content and scope. When the research on NOS is examined, it was determined that NOS understandings are affected by factors such as personal characteristics [38], world views [46, 55], learning trends and beliefs [27], NOS concerns and intellectual levels $[8,56]$, motivation $[46,57]$ metacognition [11, 58, 59], decision-making skills [60], familiarity with NOS [61], positivist understanding of science [54, 62], argumentation [63], values and assumptions [6]. So, NOS is affected by many factors. Teachers' NOS understandings are decisive on whether or not they will teach in accordance with the contemporary paradigms of science. Therefore, the facilitating and coercive effects of such factors should be considered during the teaching of NOS. A teacher who wants to provide students with sufficient NOS understandings must firstly be sure that their own understanding is sufficient enough [6, 64]. Effective science teachers are expected to teach NOS not only by using traditional instructional tools but also by making use of useful forms of representations, salient analogies and examples in the context of the history/philosophy of science [41]. However, this is not in harmony with the findings of the relevant literature to some extent. One of the factors that make it difficult is having a traditional view of science [56]. In her work, Brickhouse [62] stated that both experienced and inexperienced teachers evaluate science and the scientific method in terms of the positivist paradigm of science, and they regard the scientific method as a series of tools that leads us to absolute scientific knowledge. However, it was reported that experienced teachers think students can attain informed NOS understandings [65]. Cetin [66] reached similar results with the scientific method. As a result of their analysis, it was seen that prospective science teachers interpret the scientific method under the themes of the way of determining the reality, the means of conducting experiments, previously fixed steps, the way that scientific authority approves and the understanding of contemporary science. Additionally, prospective teachers stated that scientific methods that are used in science teaching are different from other sciences. Similarly, Turgut [54], in their study which examined the understandings of scientific knowledge and the scientific method, found that prospective science teachers evaluated scientific knowledge within the framework of the absolutist/realistic science paradigm and had myths about the scientific method. It was seen that, when prospective teachers were describing scientific knowledge, especially when they were asked what distinguishes science from the other disciplines of thinking, they often talked about experimentalism, objective observations, certainty and being proven. It was determined that prospective teachers see philosophy as a set of personal interpretations which are not certain. One of the interesting findings is that non-science inquiry disciplines are not known, and misconceptions about them are common. Authors noted that the lack of knowledge that curious scientists could be seen as philosophers nourishes one-sided science. Turgut, Eş, Bozkurt Altan and Öztürk Geren [67] conducted a similar study in the context of prospective early childhood teachers. It was observed that they also emphasized concepts such as proving something by scientific research while defining science. Therefore, it was concluded that science is evaluated from a traditional framework as a way of knowing revealing precisely defined realities that works in a limited area. In a study where the reasons for having a traditional understanding of science were investigated, Akerson and Donnelly [38] found that 
tradition-bound prospective primary school teachers consider science as a dualistic activity rather than a process-oriented activity [27], and they tend to have insufficient understandings in terms of the tenet of scientific knowledge as being tentative [46]. Based on the idea that process-oriented thinking requires activation of the higher cognitive mechanisms and the progress in the stages of moral development [29], metacognitive strategies for understanding the tentative nature of scientific knowledge are also effective [11]. In another study, it was stated that prospective teachers could not produce counter-arguments while discussing socio-scientific issues, and this might be due to having insufficient understandings on the tentative characteristics of scientific knowledge [63]. Kaya [68] examined the NOS understandings of prospective early childhood teachers by comparing them to those of prospective primary school teachers. Their study showed that the former group did not have a sufficient understanding on the basis of evidence-based scientific knowledge and could not clearly articulate the relationship between theory and law. As a result of the study, it was corroborated that prospective primary school teachers have misconceptions similar to early childhood teachers despite the fact that prospective primary school teachers have more science courses, and they have directly participated in the teaching practices of the nature of direct reflective science. Akerson, Buzzelli and Donnelly [8], who examined the reflections of these understandings on teaching practices, examined the instructional practices of prospective early childhood teachers. It was determined that the factors that facilitate or impede their teaching practices are primarily mentor teachers at the co-operating schools and the science education program accompanying teachers. It may be stated that prospective early childhood teachers' understandings on scientific knowledge and the scientific method may vary based on their teaching experiences and what orientations they have in teaching NOS [36].

The results obtained from previous studies showed that prospective early childhood teachers, like other prospective teachers, had inadequate understandings on NOS. The reasons for this situation about prospective early childhood teachers may be listed as follows: a) they do not take a course directly in science [67]; b) they do not perform the same laboratory activities that prospective science teachers do; c) they take courses in the social sciences as opposed to prospective science teachers; d) the epistemological origins of the courses they take on the undergraduate level are different from the natural sciences. In addition to this, in-depth studies of prospective early childhood teachers' understandings on scientific knowledge and the scientific method are not encountered often $[8,38,56,67,68]$. Based on previous findings, students on the level of early childhood can develop their views on NOS $[33,38,39,40]$. Therefore, an in-depth study of this phenomenon on this level is needed. Prospective early childhood teachers' understandings on scientific knowledge and the scientific method were considered important, and the study was conducted with prospective early childhood teachers.

In accordance with the overall discussion above, this study was prompted by the following research questions:

1. What are prospective early childhood teachers' views on the nature of scientific knowledge?

2. What are prospective early childhood teachers' views on the nature of the scientific method?

3. What are prospective early childhood teachers' views on the relationship between scientific knowledge and the scientific method?

\section{Materials and Methods}

\subsection{Model of Research}

The majority of the studies in the relevant literature revealed that prospective teachers have inappropriate understandings on scientific knowledge and the scientific method in the context of NOS. This problem becomes more complicated when it comes to prospective early childhood teachers. This is because it is known that science-related courses in prospective early childhood teachers' curricula are limited in terms of both number and course hours. Therefore, it is thought that qualitative-interpretive studies, which examine the understandings of prospective early childhood teachers on scientific knowledge and the scientific method in detail, are needed, because we expect prospective early childhood teachers to have informed NOS understandings, but we cannot support them adequately through teaching programs. Accordingly, the main purpose of this qualitative-interpretive study was to explore their NOS understandings in terms of scientific knowledge and the scientific method [1,69]. Accordingly, the study focused on the meanings that they ascribed to both scientific knowledge and scientific method.

\subsection{Sampling}

This study was carried out with 10 third-year prospective early childhood teachers receiving undergraduate education at a state university in southeastern Turkey and selected by purposive sampling. At the end of this program, prospective teachers who successfully complete their undergraduate courses get a BA degree with certification for teaching on the early childhood level. The reason for the selection of prospective teachers in the third year was that they had taken the Scientific Research Methods Course in the aforementioned academic period. Academic achievement criteria were used in the selection of the sample. As the 
current academic averages were considered as criteria, the last academic grade point average value of the prospective teachers was reached, and the five most successful prospective teachers were selected. The rest was chosen among the ones with the lowest average in the same class. All participants were given a letter as a code in the analysis. These letters were accompanied by $(+)$ or $(-)$ if they were categorized as high or low academic achievement, respectively. The prospective teachers who voluntarily participated in the study were women, and none of them had previously taken any NOS or philosophy of science courses. When the cities where the prospective teachers came from were examined, it was seen that most of them came from the city where the university is located, and the remaining ones came from other cities in the region. Therefore, it may be stated that the prospective teachers had similar opinions and value judgments, and their social reality perceptions were formed similarly by the influence of the surrounding social dynamics.

\subsection{Data Collection}

The data collection process should be carried out in the context of qualitative research since it aims to provide an in-depth analysis of the meanings attributed to scientific knowledge and the scientific method by the participants. The data were collected through focus group interviews to address the research questions in the study [70]. The interviews were conducted in three subsequent meetings, and each meeting lasted approximately 35-50 minutes. All interviews were analyzed by two researchers who worked separately. Notes were taken at these meetings. In these interviews, firstly, the participants were introduced to an interview protocol. The interview protocol included various open-ended questions aiming to reveal meanings ascribed to scientific knowledge and the scientific method. Prior to the interviews, the prospective teachers were required to express their views more clearly and answer the questions sincerely. During the interviews, all questions in the form were discussed one by one in the presence of all prospective teachers.

\subsection{Data Analysis}

The data were analyzed based on the participants' responses to the open-ended questions in the semi-structured forms. Furthermore, the data that were obtained were analyzed again through the analytical approach proposed by Marshall and Rossman [1], respectively in accordance with the description, classification and association steps. In this approach, the idea that prospective teachers' views are influenced by the social context and therefore should be examined in the social reality dimension is advocated. This view argues that the social context consists of groups, organizations, institutions and cultural components. Thus, it is assumed that the science perceptions of prospective teachers within the social reality dimension are influenced by the social context and shaped accordingly [71]. First of all, description was carried by the prospective teachers' responses to the open-ended questions. Then, classification was made by considering these described data in turn. In other words, related categories were created by coding. Finally, it was aimed to reveal the existing or possible relationships between the responses. In the coding process, it is worth to noting that the researcher should consider the research questions or the conceptual framework of the research so that they should be constantly aware of what is being sought in the data [45]. For this reason, the responses to each question by the participants were transcribed. The analysis of the qualitative data that were obtained through focus group interviews was divided into main categories and subcategories in line with the framework proposed by Marshall and Rossman [1] through analytical induction. Later, the main categories were coded as "strand", and the categories were also coded as proposed by Bennett, Rollnick, Green and White [72]. Coding was achieved by open coding (line-by-line coding). The flow diagram summarizing the data analysis process is given in Figure 1. 


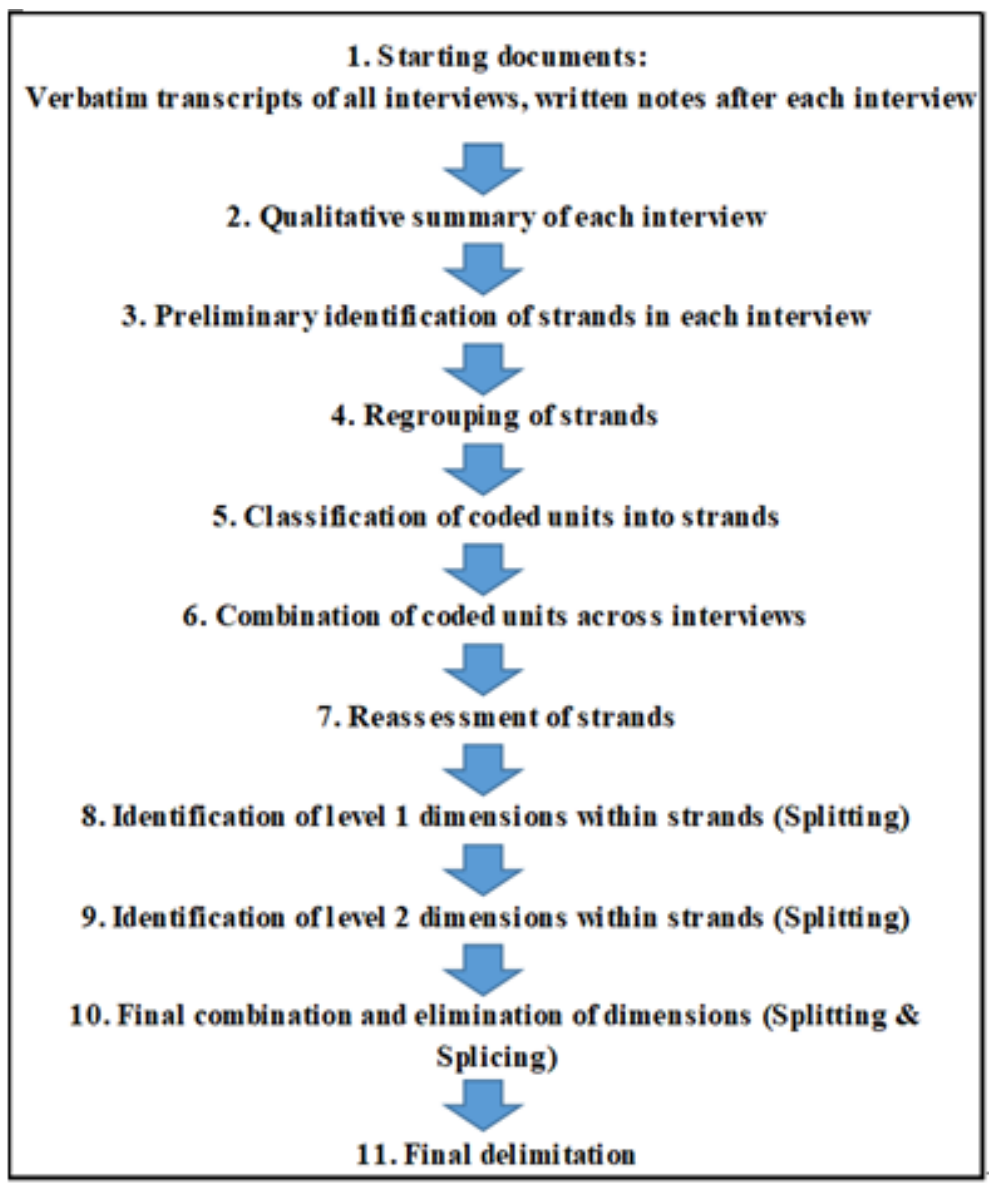

Figure 1. Flow diagram used in the analysis of the interviews

The analysis process consisted of ten basic steps following each other in a hierarchical order. As the strand was predetermined, the researchers started the analysis in this study from the fifth step. After separately completing the analyses, the authors met to compare their findings. Discrepancies were strictly debated and interpreted in their discussions until they collusively managed to get a consensus. The categories and related codes emerged through a rigorous-iterative process of engagement and reengagement with the data [73].

\section{Results}

The results are presented in association with the three research questions. In this section, the participants' NOS understandings are analyzed in terms of two concepts: a) the nature of scientific knowledge and $b$ ) the nature of the scientific method. The focus is on how the participants interpreted the relationship between scientific knowledge and the scientific method that produced it. As the participants' understandings on these concepts are analyzed in-depth, the qualitative research method was utilized. In general, it was clear in the analyses that the participants held a positivist comprehension of science. The understandings of the participants that were far away the paradigm of contemporary science bore the traces of perception of basic reality, and these arguments were also interpreted under the positivist approach. Unlike the requirements specified by Abd-El-Khalick and Lederman [74], many of the participants emphasized the characteristics of deterministic scientific comprehension and ignored the theory-laden characteristics of observations in the process of constructing scientific knowledge. They did not know that the superiority of the scientific method is derived from its epistemological origin, and they had justification and logic based opinions concerning the scientific characteristic of knowledge that is produced through the scientific method. The understandings of the participants on the nature of scientific knowledge and the scientific method are analyzed in two separate categories under the first strand. Additionally, these categories emerged as the collection of the preliminary codes given below in Table 1:

As shown in Table 1, many emergent codes were detected. The analysis provided support that both scientific knowledge and the scientific method are considered in the realm of the positivist paradigm with codes such as compulsory way of science, the right methodologic way, tangible knowledge, end product and traditions. These codes were divided into two strands given in Table 2, and the analyses were carried out accordingly. 
Table 1. Preliminary codes in the analysis

\begin{tabular}{ll}
\hline Preliminary codes & Preliminary codes (continued) \\
\hline Compulsory way & Hypothesis \\
\hline Universal validity & Interpretation \\
\hline Basic reality & Scientific revolution \\
\hline Scientific authority & Criticism \\
\hline Scientific approval committee & Observation \\
\hline Pragmatism & Proved facts \\
\hline The right way & Technological advancement \\
\hline Aimless way & Experiment \\
\hline Falsification & Everyday coping \\
\hline Methodological validity & Proved method \\
\hline Precise result & Subjectivity \\
\hline Error rate & Universal consent \\
\hline Relative validity & Textbooks \\
\hline Concreteness & Experiences \\
\hline Needs & End product \\
\hline Testing & Personal opinion \\
\hline Usefulness & Objectivity \\
\hline Point of view & Contextuality \\
\hline Reliability & Traditions \\
\hline & \\
\hline
\end{tabular}

Table 2. Categories related to each strand

\begin{tabular}{|c|c|}
\hline Strand & Category \\
\hline \multirow{2}{*}{ Scientific Knowledge } & Empirical \\
\hline & Tentative \\
\hline \multirow{9}{*}{ Scientific Method } & Natural sciences/social sciences \\
\hline & Instrumentalism/functionality \\
\hline & Universal steps \\
\hline & Experiment/observation \\
\hline & Determinist/absolute confirmation \\
\hline & Epistemological presuppositions \\
\hline & Cultural background \\
\hline & Universal committee approval \\
\hline & Observation bias \\
\hline
\end{tabular}

\subsection{Understandings on the Nature of Scientific Knowledge}

The results in relation to the nature of scientific knowledge revealed two categories as empirical and tentative. The findings are presented by means of these tenets accordingly. In the first place, the findings regarding the participants' arguments on the nature of scientific knowledge through the traditional/contemporary science paradigm are covered here. The following dialogue, on whether scientific knowledge is adaptable or not, took place between the participant B(-), who had the misconception that universal steps existed in relation to the scientific method, and the researcher:

Participant: In order for a piece of knowledge to be considered scientific, it has to go through the same path. Everyone needs to perform certain universal steps.

Researcher: What do you think these steps are and how they work?

Participant: In fact, initially, the goal is determined. The second step is the purpose. No matter what the subject is, everyone should pass through these steps. After that, a hypothesis is created. Then, you can start 
collecting data.

Researcher: You mean the hypothesis should be tested?

Participant: Yes, the hypothesis should be tested, it is somewhat an experiment stage. If science is concerned, an experiment is carried out, but the social scientist observes. In order to reach an objective result, they make observations at different places and maybe in different environments. Finally, the hypothesis reveals the assumption.

Researcher: Assumption? What do we do with the hypothesis?

Participant: It is either confuted or not.

Researcher: Is it corroborated?

Participant: It can be corroborated or not. If it is corroborated, then you can progress on it.

Researcher: What happens then? What happens when you corroborate a hypothesis?

Participant: You prove it.

Researcher: And?

Participant: It is theorized.

In the dialogue above, it is noteworthy that the participant supported their point of view that universal steps are used during scientific research, with the argument that "everyone, regardless of the subject, does the same". At the following stage, the participant divided their argument into two, in terms of science and social sciences. As a matter of fact, the participant categorized an experiment as a means of validation in the field of science, while considering the testing of a hypothesis and categorizing observation into the social sciences field. The participant said to have the ideological pivots of credulous experimentation while referring to test directly in the testing of hypotheses, and she had pivots of blind idealism, while categorizing the experiment in the field of science, and while giving the impression that it will produce precise and objective knowledge in this field. Finally, the participant mentioned the hypothesis, as being proven only upon corroboration and turning into theory. Given their arguments that has been discussed so far, it may be stated that the participant had a perception of universal steps of methodology regarding scientific knowledge. Additionally, they addressed the process of science as different regarding science and the social sciences as well as considering an experiment as a tool that produces objective knowledge in the field of science. This situation may be interpreted in particular that the dynamics of the nature of scientific knowledge are in need of analysis.

The participant $\mathrm{T}(-)$, who associated the perception of objective science with real science and claimed that scientific knowledge is produced this way, defended the following arguments regarding the nature of scientific knowledge:

"I think modern science is closer to real science. Real science produces real knowledge. Real knowledge is more tangible, and it tries to remain tangible. What is true is, the value we give to that knowledge. If that glass is there, it's there. Knowledge also exists this way."

The interview excerpt above shows that $\mathrm{T}(-)$ perceived knowledge epistemologically as a structure that exists in a tangible way outside the human mind. While talking about real knowledge, they structured the approach of contemporary science, in which they altered as a real science based on the assumptions of the positivist approach to science by adding on the tangible characteristics of knowledge to their words. The participants who perceived scientific evidence as the proof of the fact that scientific knowledge cannot be altered, stated to have ideological pivots of naive realism. From their point of view, science definitely produces accurate knowledge.

The following dialogue on the transition from theory to law took place between the researcher and the participant coded $\mathrm{N}(-)$, who had a misconception on the universal steps of the scientific method and considered the test stage to be the final verifier:

Researcher: So, briefly, you're talking about combination of methods, but the difference of results! Well! Let's talk about the hypothesis. Let us clarify the concepts of assumption and hypothesis. It's not the assumption we construct a hypothesis! Isn't that so? The hypothesis is constructed. In other words, "denence" in Turkish. We test the hypothesis; it is either right or wrong. Hmm... What happens when a hypothesis is corroborated?

Participant: If a hypothesis is corroborated, it becomes a law. Einstein, for instance, has two theories of relativity. I remember them. They have not become laws, for example; they have remained in theory. Because they are still being experimented on, or technology has not yet reached a solution. When experiments reach a solution, the hypotheses will then become laws.

Researcher: So, we have now corroborated the hypothesis, and it becomes a theory. Following this stage, we have found an opportunity again to re-test it based on new data. What about the theory then? The evolutionary theory, for instance? Or kinetic theory? What happens when they are backed up with different evidence and proven in all respects?

Participant: You mean what happens to scientific knowledge?

Researcher: We have already believed in its scientific nature. So, it is theorized. The theory is supported with consistent data. Is it a law now?

Participant: Yes, it is a law now. There is a hierarchical order.

The participant who emphasized that there is an objective method that has been accepted by everyone defined theories as open to change and laws as unchangeable over time. When the participant stated that 
"Einstein's theories are not laws. Because, they have remained as theories", they refer to the term "staying in theory" as the inability to reach a law which they considered to be the most valid kind of scientific knowledge. According to the participant, the fact that the knowledge that remains in theory may be subject to change, was not primarily associated with the evidence obtained through observations of the natural world. It seemed to be related to the horizontal meaning expansion in the context of the scientific method, which is so-called the universal steps. It would seem plausible that the participant interpreted this process in accordance with the possible arguments they acquired from environmental sources (such as family, school, friends, textbooks) rather than evidence-based reasoning. Consequently, they described a theory so called as "remaining as a theory" as a piece of knowledge located on the hierarchically lower levels than a law.

In accordance with the overall discussion above, it is noted that nearly all participants took their positions on the basis of universal steps of the scientific method while discussing the qualifications of scientific knowledge. It was found that the participants, who degraded the methodological process producing scientific knowledge to the experimental dimension only, had poor achievements regarding their academic background. However, the participants with high academic achievement levels also had positivist interpretations of the mechanisms that produce scientific knowledge, and they had similar ideological pivots to those with low academic achievement. Therefore, discussions on the nature of the scientific method were also found important since both groups tended to discuss their views on scientific knowledge through the scientific aspects of the methods.

\subsection{Understandings on the Nature of the Scientific Method}

The results in relation to the nature of the scientific method revealed nine categories as natural sciences/social sciences, instrumentalism/functionality, universal steps, experiment/observation, determinist/absolute confirmation, epistemological presuppositions, cultural background, universal committee approval and observation bias. The findings are presented by means of these tenets accordingly.

The understandings of the participants with poor academic achievement are initially included in this section where the participants' arguments on the nature of scientific method are examined within the framework of the traditional/contemporary science paradigm. It was determined that nearly all the participants covered in this group emphasized arguments on the positivist paradigm during the interviews, and they tended to handle the scientific method from this point of view. Similarly, it was found that the participants regarded the knowledge constructed through scientific methods more valuable than that constructed by other methods. E(-)used the term " $a$ compulsory way to be used" when they talked about the scientific method. They stated that it is important whether the scientific method is goal-oriented or not, rather than whether it is accurate or not. The participant exhibited a pragmatic attitude emphasizing that meticulously collected data will yield useful results if there is nothing mistaken. In accordance with the notes held by the researcher during the interviews, it was reported that the participant was frequently trying to relate the terms of certainty and objectivity. It may be stated that this statement was consistent with their argument that there exists a common, universal method. The same participant stated that, as we conduct scientific research while we cannot develop any method of our own, we need to use existing methods. This is supported by the idea that methods can only be developed by scientists, since they should be valid and have reliable results. At the first glance, this argument seems to be in line with the contemporary paradigm of science. However, as the interviews progressed, the participant began to justify the same situation with the fundamental assumptions of the positivist approach, during the focus group interview, with the possible effect of the arguments shared among their peers. When the participant was questioned on why the scientific method is more valid than other methods, they noted that scientists conduct their work in an objective way, and they do not add their own ideas and bias to their research. In other words, the participant associated the validity of the scientific method with absolute objectivity. The idea that only the methods developed by scientists may be scientific, and a single individual cannot produce scientific methods revealed the participant's point of view as there is a cultural difference between scientists and others. The participant $\mathrm{Tu}(-)$ emphasized specific objectivity in relation to each method rather than the objectivity of the scientists applying the scientific method. According to this participant, the more objective the method used, the more accurate scientific knowledge can be obtained. $\mathrm{T}(+)$ rejected the universal steps advocates saying that the situation where it is only possible to reach the desired results by means of a universally accepted uniform method may not be possible in any case, and added that the same results may be achieved through different methods. It may be stated that this argument, in part, bears the traces of the interpretative paradigm. Since the participant was quite aware of methodological pluralism which is one of the significant concepts of the contemporary paradigm of science, the researcher asked the participant to elaborate on their arguments. The participant justified their arguments upon this request under positivist assumptions, and within the context of objectivity and verification. Towards the end of the interviews, the participant approved the opinion of a peer who stated that the use of different methods would ultimately enable us to reach the same result. Moreover, 
they repeated the view that the same result would be achieved by using different methods provided that one does not make a mistake. Therefore, since the participant was talking about alternative methods for predetermined results, it was deduced that they had an understanding of the method in accordance with the deterministic point of view. $\mathrm{G}(+)$ contrary to the previous views, referring to the point that the scientific method may not lead to an absolute right. Therefore, during the interviews, they often rejected the expression of the "proven approach". Because, according to this participant, the universal committee approval, which is one of the arguments that emerged during the interviews, cannot guarantee that the method will get to absolute conclusions. The participant, in defending this argument, emphasized that there is no scientific method can provides ever-proven knowledge since it is impossible to have a definitely proven method. It is noteworthy that the arguments of the participant exhibiting a stance close to the interpretive paradigm, began to change in favor of the positivist approach as the interview progressed and as they were exposed to peer discussion. Unlike previous participants, $\mathrm{M}(+)$ highlighted the concept of "participant role", as the researchers who apply the scientific method are observers. According to the participant, the role of the subject is definitely significant regarding not only the knowledge produced by the methods, but also regarding the selection criteria and implementation of the methods. Defending importunately that the aforementioned methods are ultimately a product of the human mind, the participant stated that observers have certain perspectives, contrary to the positivist paradigm. Surprisingly, the participant tried to define the scientific method in accordance with the positivist concepts such as the "right way", "the way that should be universally accepted", and "the way not corresponding to the original purpose". We may conclude that this situation is an unstable equilibrium of the understandings pertaining to the contemporary paradigm of science. This balance strengthens the assumption that it is influenced by concepts that are common in the social environment with which they are associated (e.g. the focus group participants) and that divert positivist comprehension of science.

\section{Discussion and Conclusions}

The discourse that is used in the process of constructing scientific knowledge is of great importance. The idea that the evidence from the observations of the natural world is the fundamental criterion that distinguishes science from other research disciplines constitutes the backbone of the scientific explanation production mechanism of scientific discourse [13]. Different explanations on the same phenomenon may be produced during scientific activities. Individuals who consider that each of these may also be valuable are expected to believe that arguments with stronger evidence are more valuable, and thus, realize that scientific knowledge is tentative [75]. However, the result of this study was that prospective early childhood teachers had many misconceptions regarding science, scientific knowledge and the scientific method. In consideration of these prospective teachers, this finding was similar to those in the literature $[11,13,32,38,46]$. Specifically, the first research question focused on the participants' understandings on the nature of scientific knowledge. Evidence-based conclusions that are obtained through systematic and peer-reviewed observations serve to construct scientific knowledge after being subjected to various mental processes. Any knowledge refined through mental processes has to be of theory-laden. Therefore, any knowledge constructed by individuals with a limited processing capacity is intrinsically open to change in social reality, even though it is durable and reliable. As noted earlier, the basic point of view that distinguishes science from other disciplines is that scientific knowledge is only based on evidence in terms of tentativeness. In other words, theory-laden knowledge grounds its criteria of change by being evidence-based [26, 42]. This is the main impulse regarding the tentative nature of scientific knowledge. At the same time, current scientific knowledge may change as a result of the reinterpretation of the available evidence. The development of technology may facilitate the process of obtaining scientific knowledge. However, the results achieved through existing or new evidence rather than pure technological progress are also important regarding the change of scientific knowledge. In this study, most participants did not perceive the basic function of evidence and confused the evidence with results. Moreover, the participants often demonstrated the needs and technological developments affecting the development of scientific knowledge and methods. None of the participants indicated evidence of the observation of the facts as a source. In other words, the participants interpreted that the criterion differentiates science from other research disciplines as needs and technological progress, spontaneous development of science and methods, rather than being evidence-based. Contrary to this argument, science proceeds both cumulatively and revolutionarily in the form of interpreting data obtained through relatively more valid and reliable measurements of the methods developed in accordance with the evidence that has been obtained. The findings on prospective teachers who regarded science as equivalent to technological progress are common. Another finding was that the participants were trying to explain the process of constructing scientific knowledge upon deterministic/absolutist concepts [74]. This situation may be interpreted as that the participants exhibited positivist attitudes epistemologically [62]. On the other hand, unfortunately, no participant emphasized that scientific knowledge is constructed under various epistemological and ontological limitations and is not alleged to solve 
every problem. This indicates an important problem. This is because it is necessary for teachers, who have a role in generating and guiding the process of obtaining scientific knowledge in the classroom environment through activities involving questioning, to mention frequently that it is worthy, together with the limitations of these concepts when directing students' concepts related to science. Indeed, science along with its limitations is a valuable interdisciplinary field of study [6]. Science is also a verification activity affected by the context of discovery. During this activity, the causal relationships on and in between cases are determined in an empirical way and the hypotheses created to meet these relationships are again tested through cases. This gradual structure actually points to the scientific method. The scientific method may be considered under two different approaches. The epistemological approach is the opinion that science is the highest competent tool among other research areas. It is emphasized that, perception of science as an occupation of natural phenomena may lead to the denegation of the fact that there are different sciences and different scientific methods $[20,42]$. As a matter of fact, in consideration of the arguments as of the participants in this study, they revealed a distinction between science/social sciences, and there were observations on the use of scientific methods which had universal steps especially in the field of natural sciences. From the point of view of the tentative characteristics of scientific knowledge, contrary to the expectations, the participant with high academic achievement referred to the idea that knowledge can only change due to scientific and technological advances, whereas the participants with lower academic success, beyond the needs, said that the data that are obtained and reinterpreting these advances science. The same situation was observed on the student level [53]. There are studies in the literature confirming an increase of understandings to some extent in terms of the evidence-based and tentative characteristics of scientific knowledge [76]. Although there are various and concurrent activities implemented together with manipulative interventions, there are also studies reporting that the development of students' understanding, regarding the tentative and evidence-based characteristics of scientific knowledge, is more difficult [77]. This may also apply to prospective teachers [78]. However, there is evidence that conceptual change strategies may be effective in overcoming this difficulty [28].

In response to the second research problem, the participants' understandings of the scientific method in general were found to be influenced by a traditional comprehension of science. There were judgments determining that the knowledge obtained through the scientific method is more reliable than those obtained through other means, and it will not change. These understandings are frequently encountered in the literature. Teachers with this misconception tend to follow a uniform approach and believe that the knowledge obtained through scientific methods does not change. There are some arguments defending the idea that similar ways should be pursued in science, regardless of discipline, and this way, science is perceived as a field where certain and desired results are achieved. Therefore, there is no room for imagination and creativity regarding the use of the scientific method. With the participation of this pair, the scientific characteristics of this knowledge may gradually decrease and eventually become subjective. On the other hand, the participants were determined in mentioning whether the scientific method was functional and goal-oriented. However, there were some arguments stating that this functionality would gain meaning if the goal-oriented data were meticulously collected, and this knowledge would eventually bring us closer to objective knowledge. It may be stated that the participants who defended this argument were influenced by blissful empiricism. According to them, science becomes worthy under a single reality, and errors originate from carelessly conducted scientific processes rather than science itself [79].

Another important finding obtained through this study was the argument that results may be reached through experimentation, which is a manipulated type of observation rather than evidence. It was determined that almost all the participants considered experiments as a final evidence tool in the field of science. The participants argue that the knowledge in the field of the natural sciences is more precise than that in the social studies, hence, arguments were dominant rather than evidence in accordance with the social sciences. In line with this view, it is necessary to react normally when participants think that subjectivity is influential in the process of constructing knowledge through methods of the social sciences, and in turn, it decreases the scientific value of such knowledge. Rather, the objective knowledge is to review the perceptual and inferential characteristics of objective phenomena. Contrary to the popular belief, it is important that science targets objective phenomena rather than being objective itself. In other words, the fact that we make use of our own observations while making inferences (not to include personal interpretations or bias in scientific activities) does not reduce the objectivity of science [42]. Frequently, students perceive an experiment as a means of proof rather than an observation tool. Evidence obtained through experiments is frequently confused with the results obtained through them. We may say that evidence alone has little voice in the validity and reliability of a theory. This in particular paves the way for theories to be particularly reproducible and open to testing [13]. It may be emphasized that the participants believed that evidence itself can confirm a hypothesis that serve theories. This means they had ideological pivots with credulous experimentation. The participants who thought that carefully conducted experiments will produce 
flawless and precise scientific knowledge are considered to be the owners of the blissful empiricism ideological pivots.

Considering studies in general terms, it is foreseen that researchers dwelled on insufficient understandings regarding science, scientific knowledge and the scientific method within the concept of NOS, and ways to overcome these were sought. These inadequacies are mainly due to a positivist comprehension of science. Assumptions based on ontological and epistemological origins are misinterpreted and grounded on arguments. It is another problem to perceive the scientific process in dichotomy rather than a process-oriented understanding on science [38, 46]. At the same time, another factor that diversifies misconceptions is the fact that prospective teachers have different world views $[46,55]$. This may lead to various problems in practice. Firstly, teachers as commonly expressed in the literature cannot teach what they do not know and what they have misconceptions about [41]. However, teachers have great responsibilities in the development of scientific literacy, which has become a common goal of science curricula. It is frequently debated that teachers have a great influence on the ability of students to achieve meaningful learning outcomes thanks to the teaching activities they perform both inside and outside the classroom. Therefore, in order to develop students' understanding of science from an early age, it is necessary to focus on the need for teachers who design a learning environment open to collaborative and social interaction. One of the cornerstones of developing scientific literacy is teaching NOS. However, the assumption that teachers who have an understanding of informed science teach NOS better is not guaranteed [53], and they have been reported to have a tendency to avoid teaching through a lesson plan related to NOS [80]. Teachers usually put forward problems such as deficiencies in classroom management, lack of self-confidence, problems with school management and some material resource deficiencies as some of the rationales for these tendencies [9].

\section{Recommendations}

The responsibility of prospective early childhood teachers who educate preschool students at the age of beginning to develop basic scientific process skills is very important. In this period, the development of fundamental skills regarding science should be explicitly targeted. As a matter of fact, it may be observed that students of this age can develop their NOS understandings and reflect these views in their daily lives [38, 39]. In order to achieve this, first of all, in-service and prospective teachers should develop their own informed NOS skills. However, it is frequently reported that teachers who are supposed to be competent to teach science and prospective teachers who are likely to serve such an instruction in the future have flawed understandings in relation to scientific knowledge and the scientific method. This is reflected in the findings of this study as noted earlier. Therefore, various recommendations may be made within the context of prospective early childhood teachers. They do not have the opportunity to receive explicit teaching on reflective NOS during their undergraduate studies. This constraint is the primary obstacle in developing their informed NOS understandings. Thus, it is clear that there is a need for education in terms of teaching the context-based nature of science supported by rich content. During these context-based courses, prospective early childhood teachers may be supported through explicit teaching on, a) the real functions of experiments, b) processes on how scientific experiments are conducted in different research subjects, c) definitions of the different types of scientific knowledge such as hypothesis, law and theory, within the contemporary science paradigm. Those who want to develop informed NOS skills in their classrooms should be aware that they need to establish and sustain a classroom environment specifically designed for scientific inquiry. In practice, it is observed that, especially science education on the preschool level is carried out through gaining scientific process skills rather than guided-inquiry. In order to eliminate this deficiency and increase the awareness of prospective teachers about inquiry-based teaching, it may be emphasized that in-service training programs should be extended and supported and this process should be studiously followed by the designers of curricula.

The further research would be designed to explore prospective early childhood teachers' approaches to inquiry-based learning. Therefore, we recommend increased emphasis to be placed on NOS tenets and their epistemological underpinnings in the curricula. Additionally, further research is needed to explore the effect of having informed science content knowledge related to NOS tenets and its translation into instruction. The latter specifically refers to pedagogical content knowledge for NOS. This teacher knowledge base in relation to science instruction enables researchers to elicit prospective teachers' beliefs on both NOS and NOS teaching in the light of orientations to science teaching [39]. In fact, studies that focus on the orientations to science teaching of prospective early childhood teachers are scarce and this gap needs to be given further consideration. Finally, it was deducted that ideological pivots on science are not sufficiently questioned in the relevant literature. Moreover, developmental psychology is not sufficiently utilized, and arguments on NOS are evaluated in a narrow scope generally based on epistemological beliefs. For this reason, it is recommended to conduct studies to analyze the relationships of prospective early childhood teachers' science-related schemes in particular [81] and arguments 
on NOS in accordance with their ownership of ideological pivots [79], a process-oriented, relative NOS understanding in terms of higher cognitive capacity and relevance to its use [29].

\section{REFERENCES}

[1] Marshall, C., \& Rossman, G. (2006). The how of the study: Building the research design. Designing qualitative research, 55-101.

[2] Khishfe, R. (2013). Transfer of nature of science understandings into similar contexts: Promises and possibilities of an explicit reflective approach. International Journal of Science Education, 35(17), 2928-2953.

[3] Lederman, N. G., \& Abell, S. K. (Eds.). (2014). Handbook of research on science education (Vol. 2). Routledge.

[4] DeBoer, G. E. (2000). Scientific literacy: Another look at its historical and contemporary meanings and its relationship to science education reform. Journal of Research in Science Teaching: The Official Journal of the National Association for Research in Science Teaching, 37(6), 582-601.

[5] Lederman, J. S. (2007). Development of a valid and reliable protocol for the assessment of early childhood students' conceptions of nature of science and scientific inquiry. Saarmste Executive, 446.

[6] Lederman, N. G. (1992). Students' and teachers' conceptions of the nature of science: A review of the research. Journal of research in science teaching, 29(4), 331-359.

[7] Driver, R., Leach, J., Millar, R., \& Scott, P. (1996). Young people's images of science. Buckingham, England: Open University Press.

[8] Akerson, V. L., Buzzelli, C. A., \& Donnelly, L. A. (2010). On the nature of teaching nature of science: Preservice early childhood teachers' instruction in preschool and elementary settings. Journal of Research in Science Teaching: The Official Journal of the National Association for Research in Science Teaching, 47(2), 213-233.

[9] Abd - El - Khalick, F., Bell, R. L., \& Lederman, N. G. (1998). The nature of science and instructional practice: Making the unnatural natural. Science education, 82(4), 417-436.

[10] Rudolph, J. L. (2000). Reconsidering the "nature of science" as a curriculum component. Journal of Curriculum Studies, $32(3), 403-419$.

[11] Abd - El - Khalick, F., \& Akerson, V. (2009). The influence of metacognitive training on preservice elementary teachers' conceptions of nature of science. International Journal of Science Education, 31(16), 2161-2184.

[12] Erduran, S., \& Dagher, Z. R. (2014). Reconceptualizing nature of science for science education. In Reconceptualizing the Nature of Science for Science Education (pp. 1-18). Springer, Dordrecht.

[13] Lederman, N. G., Abd - El - Khalick, F., Bell, R. L., \&
Schwartz, R. S. (2002). Views of nature of science questionnaire: Toward valid and meaningful assessment of learners' conceptions of nature of science. Journal of research in science teaching, 39(6), 497-521.

[14] Abd-El-Khalick, F. (2014). The evolving landscape related to assessment of nature of science. In N. G. Lederman y S. K. Abell (Eds.), Handbook of Research in Science Education, Volume II. (pp. 621-650). New York, NY, USA: Routledge.

[15] McComas, W. F. (2015). The nature of science \& the next generation of biology education. The American Biology Teacher, 77(7), 485-491.

[16] AAAS (American Association for the Advancement of Science). 1993. Benchmarks for science literacy. New York, NY: Oxford University Press.

[17] National Research Council (NRC) (1996). National science education standards. Washington, D.C., National Academy Press.

[18] National Science Teachers Association. (2000). NSTA position statement: The nature of science. Document retrieved, 3(18), 03.

[19] Clough, M. P. (2006). Learners' responses to the demands of conceptual change: Considerations for effective nature of science instruction. Science \& Education, 15(5), 463-494.

[20] Özlem, D., (2016). Bilim Felsefesi [Philosophy of Science], 3. Basım, Notos Kitap, İstanbul.

[21] McComas, W. F. (1998). The principal elements of the nature of science: Dispelling the myths. In The nature of science in science education (pp. 53-70). Springer, Dordrecht.

[22] Bell, R. L., Blair, L. M., Crawford, B. A., \& Lederman, N. G. (2003). Just do it? Impact of a science apprenticeship program on high school students' understandings of the nature of science and scientific inquiry. Journal of Research in Science Teaching: The Official Journal of the National Association for Research in Science Teaching, 40(5), 487-509.

[23] Akerson, V. L., Cullen, T. A., \& Hanson, D. L. (2009). Fostering a community of practice through a professional development program to improve elementary teachers' views of nature of science and teaching practice. Journal of Research in Science Teaching: The Official Journal of the National Association for Research in Science Teaching, 46(10), 1090-1113.

[24] BouJaoude, S., Asghar, A., Wiles, J. R., Jaber, L., Sarieddine, D., \& Alters, B. (2011). Biology professors' and teachers' positions regarding biological evolution and evolution education in a Middle Eastern society. International Journal of Science Education, 33(7), 979-1000.

[25] Ozgelen, S., Yilmaz-Tuzun, O., \& Hanuscin, D. L. (2013). Exploring the development of preservice science teachers' views on the nature of science in inquiry-based laboratory instruction. Research in Science Education, 43(4), 1551-1570.

[26] Abd-El-Khalick, F., \& Lederman, N. G. (2000a). Improving science teachers' conceptions of nature of science: a critical review of the literature. International journal of science education, 22(7), 665-701. 
[27] Southerland, S. A., Johnston, A., \& Sowell, S. (2006). Describing teachers' conceptual ecologies for the nature of science. Science Education, 90(5), 874-906.

[28] Cil, E., \& Cepni, S. (2012). The Effectiveness of the Conceptual Change Approach, Explicit Reflective Approach, and Course Book by the Ministry of Education on the Views of the Nature of Science and Conceptual Change in Light Unit. Educational Sciences: Theory and Practice, 12(2), 1107-1113.

[29] Akerson, V. L., Morrison, J. A., \& McDuffie, A. R. (2006). One course is not enough: Preservice elementary teachers' retention of improved views of nature of science. Journal of Research in Science Teaching, 43(2), 194-213.

[30] Demirdöğen, B., Hanuscin, D. L., Uzuntiryaki-Kondakci, E., \& Köseoğlu, F. (2016). Development and nature of preservice chemistry teachers' pedagogical content knowledge for nature of science. Research in Science Education, 46(4), 575-612.

[31] Hanuscin, D. L., Lee, M. H., \& Akerson, V. L. (2011). Elementary teachers' pedagogical content knowledge for teaching the nature of science. Science \& Education, 95(1), 145-167.

[32] Akerson, V. L., Abd - El - Khalick, F., \& Lederman, N. G. (2000). Influence of a reflective explicit activity - based approach on elementary teachers' conceptions of nature of science. Journal of Research in Science Teaching: The Official Journal of the National Association for Research in Science Teaching, 37(4), 295-317.

[33] Akerson, V. L., \& Hanuscin, D. L. (2007). Teaching nature of science through inquiry: Results of a 3 - year professional development program. Journal of Research in Science Teaching: The Official Journal of the National Association for Research in Science Teaching, 44(5), 653-680.

[34] Akerson, V. L., Townsend, J. S., Donnelly, L. A., Hanson, D. L., Tira, P., \& White, O. (2009). Scientific modeling for inquiring teachers network (SMIT'N): The influence on elementary teachers' views of nature of science, inquiry, and modeling. Journal of Science Teacher Education, 20(1), 21-40.

[35] Akerson, V. L., Pongsanon, K., Weiland, I. S., \& Nargund-Joshi, V. (2014). Developing a professional identity as an elementary teacher of nature of science: A self-study of becoming an elementary teacher. International Journal of Science Education, 36(12), 2055-2082.

[36] Demirdöğen, B. (2016). Interaction between science teaching orientation and pedagogical content knowledge components. Journal of Science Teacher Education, 27(5), 495-532.

[37] Metz, K. E. (1995). Reassessment of developmental constraints on children's science instruction. Review of Educational Research, 65(2), 93-127.

[38] Akerson, V. L., \& Donnelly, L. A. (2008). Relationships among learner characteristics and preservice elementary teachers' views of nature of science. Journal of Elementary Science Education, 20(1), 45-58.

[39] Akerson, V. L., \& Volrich, M. L. (2006). Teaching nature of science explicitly in a first - grade internship setting. Journal of Research in Science Teaching: The Official
Journal of the National Association for Research in Science Teaching, 43(4), 377-394.

[40] Alan, Ü., \& Erdoğan, S. (2018). Of course scientists haven't seen dinosaurs on the beach: Turkish kindergartners' developing understanding of the nature of science through explicit-reflective instruction. Early Childhood Education Journal, 1-12.

[41] Shulman, L. S. (1986). Those who understand: Knowledge growth in teaching. Educational researcher, 15(2), 4-14.

[42] Yildırım, C. (2014). Bilim Felsefesi [Philosophy of Science], 3. Bask1, İmge Kitabevi, Ankara.

[43] National Research Council. (2012). A framework for K-12 science education: Practices, crosscutting concepts, and core ideas. National Academies Press.

[44] Kuhn, T. S. (1970). Logic of discovery or psychology of research. Criticism and the Growth of Knowledge, 1-23.

[45] Yıldırım, A., \& Şimşek, H. (2006). Sosyal bilimlerde nitel arastirma yöntemleri. Seçkin Yayıncılık.

[46] Abd - El - Khalick, F., \& Akerson, V. L. (2004). Learning as conceptual change: Factors mediating the development of preservice elementary teachers' views of nature of science. Science Education, 88(5), 785-810.

[47] Abd - El - Khalick, F. (2005). Developing deeper understandings of nature of science: The impact of a philosophy of science course on preservice science teachers' views and instructional planning. International Journal of Science Education, 27(1), 15-42.

[48] Matkins, J. J., \& Bell, R. L. (2007). Awakening the scientist inside: Global climate change and the nature of science in an elementary science methods course. Journal of Science Teacher Education, 18(2), 137-163.

[49] Wahbeh, N., \& Abd-El-Khalick, F. (2014). Revisiting the translation of nature of science understandings into instructional practice: Teachers' nature of science pedagogical content knowledge. International Journal of Science Education, 36(3), 425-466.

[50] Mulvey, B. K., \& Bell, R. L. (2017). Making learning last: teachers' long-term retention of improved nature of science conceptions and instructional rationales. International Journal of Science Education, 39(1), 62-85.

[51] Dagher, Z. R., Brickhouse, N. W., Shipman, H., \& Letts, W. J. (2004). How some college students represent their understandings of the nature of scientific theories? International Journal of Science Education, 26(6), 735-755.

[52] Abd-El-Khalick, F. (2012). Examining the sources for our understandings about science: Enduring conflations and critical issues in research on nature of science in science education. International Journal of Science Education, 34(3), 353-374.

[53] Khishfe, R., \& Abd - El - Khalick, F. (2002). Influence of explicit and reflective versus implicit inquiry - oriented instruction on sixth graders' views of nature of science. Journal of Research in Science Teaching: The Official Journal of the National Association for Research in Science Teaching, 39(7), 551-578.

[54] Turgut, H. (2009a). Fen bilgisi öğretmen adaylarının 
bilimsel bilgi ve yöntem algılar1. Türk Eğitim Bilimleri Dergisi, 7(1), 165-184.

[55] Liu, S. Y., \& Lederman, N. G. (2007). Exploring prospective teachers' worldviews and conceptions of nature of science. International Journal of Science Education, 29(10), 1281-1307.

[56] Akerson, V. L., \& Buzzelli, C. A. (2007). Relationships of preservice early childhood teachers' cultural values, ethical and cognitive developmental levels, and views of nature of science. Journal of Elementary Science Education, 19(1), $15-24$.

[57] Akerson, V. L., \& Abd - El - Khalick, F. (2003). Teaching elements of nature of science: A yearlong case study of a fourth - grade teacher. Journal of Research in Science Teaching, 40(10), 1025-1049.

[58] Peters, E. E., \& Kitsantas, A. (2010). Self - regulation of student epistemic thinking in science: The role of metacognitive prompts. Educational Psychology, 30(1), 27-52.

[59] Duruk, U. (2017). The effect of metacognitive strategies embedded in contextualized nature of science instruction on preservice science teachers' understandings of nature of science and the retention of these understandings. (Unpublished $\mathrm{PhD}$ thesis). Adiyaman University, Adiyaman.

[60] Sadler, T. D., \& Zeidler, D. L. (2005). Patterns of informal reasoning in the context of socioscientific decision making. Journal of Research in Science Teaching: The Official Journal of the National Association for Research in Science Teaching, 42(1), 112-138.

[61] Abd-El-Khalick, F. (2001). Embedding nature of science instruction in preservice elementary science courses: Abandoning scientism, but... Journal of Science Teacher Education, 12(3), 215-233.

[62] Brickhouse, N. W. (1990). Teachers' beliefs about the nature of science and their relationship to classroom practice. Journal of Teacher Education, 41(3), 53-62.

[63] Khishfe, R. (2014). Explicit nature of science and argumentation instruction in the context of socioscientific issues: An effect on student learning and transfer. International Journal of Science Education, 36(6), 974-1016.

[64] Abd - El - Khalick, F., \& Lederman, N. G. (2000b). The influence of history of science courses on students' views of nature of science. Journal of Research in Science Teaching: The Official Journal of the National Association for Research in Science Teaching, 37(10), 1057-1095.

[65] Smith, C. L., Maclin, D., Houghton, C., \& Hennessey, M. G. (2000). Sixth-grade students' epistemologies of science: The impact of school science experiences on epistemological development. Cognition and Instruction, 18(3), 349-422.

[66] Cetin, P. S. (2012). Pre-service science teachers' conceptions of scientific method. Journal of Teacher Education and Educators, 1(2), 257-274.

[67] Turgut, H., Eş, H., Bozkurt Altan, E., \& Öztürk Geren, N. (2016). Pre-service pre-school teachers' perceptions of science and pseudo-science. International Online Journal of
Educational Sciences, 8(1), 150-169.

[68] Kaya, S. (2012). An examination of elementary and early childhood pre-service teachers' nature of science views. Procedia-Social and Behavioral Sciences, 46, 581-585.

[69] Bogdan, R. C., \& Biklen, S. K. (2003). Qualitative research and design for education: An introduction to theories and research.

[70] Kitzinger, J. (1995). Qualitative research: introducing focus groups. Bmj, 311(7000), 299-302.

[71] Dey I. (1993) Qualitative data analysis. A user-friendly guide for social scientists. Routledge, London.

[72] Bennett, J., Green, G., Rollnick, M., \& White, M. (2001). The development and use of an instrument to assess students' attitudes to the study of science. Journal of the Southern African Association for Research in Mathematics, Science and Technology Education, 5(1), 1-12.

[73] Strauss, A., \& Corbin, J. (1990). Basics of qualitative research. Grounded theory procedures and techniques.

[74] Abd - El - Khalick, F., \& Lederman, N. G. (2000b). The influence of history of science courses on students' views of nature of science. Journal of Research in Science Teaching: The Official Journal of the National Association for Research in Science Teaching, 37(10), 1057-1095.

[75] Peker, D. (2008). Peker, D. (2008). Bilimsel açıklamalar ve argümanlar [Scientific Explanations and Arguments]. Bölüm 9. S. 265-311. Ed. Taşkın, Ö. Fen ve Teknoloji Öğretiminde Yeni Yaklaşımlar. Pegem Akademi Yayıncılık: Ankara.

[76] Metin, D., \& Leblebicioglu, G. (2015). Development of elementary 6th and 7th grade students' views about scientific model and modeling throughout a summer science camp. Education and Science, 40(177).

[77] Cakici, Y., \& Bayir, E. (2012). Developing children's views of the nature of science through role play. International Journal of Science Education, 34(7), 1075-1091.

[78] Ağlarcı, O., Sarıçayır, H., \& Şahin, M. (2016). Nature of science instruction to Turkish prospective chemistry teachers: The effect of explicit-reflective approach. Cogent Education, 3(1), 1213350.

[79] Nadeau, R., \& Désautels, J. (1984). Epistemology and the Teaching of Science a Discussion Paper.

[80] Herman, B. C., Clough, M. P., \& Olson, J. K. (2013). Teachers' nature of science implementation practices 2-5 years after having completed an intensive science education program. Science Education, 97(2), 271-309.

[81] Perry Jr, W. G. (1999). Forms of Intellectual and Ethical Development in the College Years: A Scheme. Jossey-Bass Higher and Adult Education Series. Jossey-Bass Publishers, 350 Sansome St., San Francisco, CA 94104. 